\title{
ANTISTREPTOLYSIN O TITER AND C-REACTIVE PROTEIN LEVELS IN PEDIATRIC PATIENTS OF ACUTE RHEUMATIC FEVER.
}

1. M.Phil (Immunology)

Assistant Manager Immunology

Pakistan Kidney and Liver institute and Research Center Lahore.

2. MBBS, FCPS (Immunology) Consultant Immunology Pakistan Kidney and Liver institute and Research Center Lahore.

3. FCPS, MRCP, FPRCP

Consultant Nephrology Pakistan Kidney and Liver institute and Research Center Lahore.

4. Ph.D Molecular Biology Assistant Professor Physiology \& Cell Biology University of Health Sciences Lahore.

5. MBBS, FCPS (Hematology) Senior Registrar

Pakistan Kidney and Liver institute and Research Center Lahore.

6. BSc. (Hons) Medical Laboratory Technology

Lecturer

Rahim Yar Khan

7. MBBS, M.Phil (Immunology)

Assistant Professor Immunology

The Children's Hospital and Institute of Child Health.

Correspondence Address:

Miss Sana Zainab

Pakistan Kidney and Liver institute and Research Center Lahore.

sanazainab2011@hotmail.com

Article received on:

01/03/2019

Accepted for publication:

07/12/2019

\section{INTRODUCTION}

Acute Rheumatic fever (ARF), an inflammatory disease, is a sequela of Streptococcus pyogenes. A infection. It typically manifests two to three weeks after group A streptococcal (GAS) throat infection. ${ }^{1,2}$ The common symptoms include fever, multiple joint pains and reflexive muscle movements; in very rare cases non-itchy rash, and erythema marginatum can occur. Carditis and Arthralgia accounts for the most common manifestations of ARF accounting for $30-80 \%$ and $35-66 \%$ of cases, respectively. ${ }^{3,4}$ Rheumatic carditis is the most disabling complication of ARF accounting for spectrum of manifestations ranging from myocarditis, to pericarditis and

\begin{abstract}
Sana Zainab", Nida Saleem², Adil Manzoor ${ }^{3}$, Saba Khaliq ${ }^{4}$, Anum Wasim ${ }^{5}$, Shakila Akram ${ }^{6}$,
\end{abstract} Farhana Shehzad ${ }^{7}$

STRACT... Objectives: To determine serum levels of antistreptolysin O titre (ASOT) and and Serology, Children's Hospital and Institute of Child Health, Lahore. Period: Jan 2015 to Jan 2016. Material \& Methods: Fifty clinically confirmed patients of ARF were included in this descriptive study. The samples were taken from Children hospital and Institute of Child Health after written informed consent. The sampling technique was convenient sampling. patients had titres above $200 \mathrm{lU} / \mathrm{ml}$. There was no significant association of ASOT with gender, age and arthralgia with p-value $=0.060,0.875$ and 0.473 , respectively. However, a significant Rising levels of ASOT and CRP in ARF patients might be used as an indicator of involvement of heart tissues and therefore can be used to monitor transition of rheumatic carditis into rheumatic heart disease.

\section{Key words: $\quad$ Acute Renal Failure, Antistreptolysin O Titer, C-reactive Protein.}

Article Citation: Zainab S, Saleem N, Manzoor A, Khaliq S, Wasim A, Akram S, Shehzad F. Antistreptolysin $\mathrm{O}$ titer and $\mathrm{C}$-reactive protein levels in pediatric patients of acute rheumatic fever. Professional Med J 2020; 27(7):1335-1339. DOI: 10.29309/TPMJ/2020.27.07.3336 
rheumatologic disorders, arthralgia is highly nonspecific. Nevertheless, poly-arthralgia after exclusion of other causes must be considered. ${ }^{6}$

Longo et al. highlighted the impact of socioeconomic status on the development of RHD with a prevalence of 22.2 per 1000 in children from slums versus a prevalence of 4 per 1000 in children going to city schools. ${ }^{7}$ The exact involvement of genetic predisposition is unclear in autoimmune diseases. However, few genetic factors have been found to be associated with increase susceptibility to autoimmune reactions in RHD. MHC class II present on lymphocytes and antigen presenting cells are the main component of RHD associated susceptibility, especially the $\mathrm{DR}$ and $\mathrm{DQ}$ alleles on human chromosome 6 . $\mathrm{RHD}$ is also associated with TNF-a present on human chromosome $6 .^{8}$

The diagnosis of rheumatic fever (RF) was first made by Jones criteria. The standard Jones criteria was modified in 1944 by T. Duckett Jones. ${ }^{9}$ Later on, it has been periodically revised by the American Heart Association in collaboration with other groups. ${ }^{10}$ According to latest revised Jones criteria, the diagnosis of RF is confirmed with a presence of two of the major criteria, or one major criterion plus two minor criteria along with evidence of streptococcal infection that is characterize by elevated/increased anti steptolysin $\mathrm{O}$ titer (ASOT). ${ }^{11}$ Chorea and indolent carditis are exceptions in diagnosis of RF as they themselves can indicate rheumatic fever. ${ }^{12}$

Tests that can give an evidence of Streptococcal infection include culture, rapid tests and antistreptolysin $O$ titre (ASOT). The serum levels of ASO titre are significant in pointing towards recent infection or an earlier exposure in a hypersensitive person with persistently high antibody levels. In this regard, serum levels of greater than 160-200 units are considered very high and support a diagnosis of streptococcal infection. ${ }^{13}$ C-reactive protein (CRP) is a nonspecific acute phase protein present in the blood and discovered by Tillett in 1930. The levels of CRP rise in response to inflammation and infections. ${ }^{14}$ CRP elevates significantly in acute rheumatic carditis and chronic rheumatic heart disease patients. ${ }^{15}$ The purpose of the study was to evaluate increased levels of ASOT and CRP in children of ARF and its association with clinical manifestations such as carditis and arthralgia.

\section{MATERIAL \& METHODS}

This descriptive study was conducted in the Department of Diagnostic Immunology and Serology, Childrens Hospital and Institute of Child Health, Lahore after getting approval from the Ethical Review Committee and Advance studies and Research Board of Children Hospital Lahore. The sampling technique was convenient sampling. The diagnosed fifty ARF patients with age ranging from 5-15 years were included in this study. An informed written consent was obtained from his/her guardian. Pediatric patients who fulfilled the Jones criteria were included in the study group while the patients with other autoimmune disease and malignancy were excluded. The clinical manifestation such as carditis diagnosed on echocardiography and arthritis were recorded on the basis of clinical history. Demographic data and clinical manifestation were recorded for every patient. Using the kit Human Tex ASOT, Wiesbaden, Germany, the ASOT > 200IU/ml was taken as positive and according to kit Human Tex CRP Wiesbaden, Germany the CRP $>6 \mathrm{mg} / \mathrm{l}$ was taken as positive.

The data was entered and analyzed using SPSS 25.0 (Chicago, USA). For quantitative variables, mean \pm standard deviation (SD) was calculated such as age. For qualitative variables, frequencies and percentages were calculated. Chi-square test was applied to observe association between qualitative variables. A $p$-value of $\leq 0.05$ was considered as statistically significant.

\section{RESULTS}

Out of 50 ARF patient, 32(64\%) were males and $18(36 \%)$ were female, making a male to female ratio of 2:1. The mean age of male and female participants was $10.03 \pm 2.43$ years and $10.33 \pm 1.57$ years, respectively. Out of these patients, $33(66 \%)$ patients fell in the age group $5-10$ years while $17(34 \%)$ patients belonged to $10-15$ years age group. A total number of $44(88 \%)$ 
ARF patients developed carditis whereas 6(12\%) patients did not show any signs of carditis. Similarly, 44(88\%) had arthralgia and 6(12\%) did not have any joint related symptoms. Considering $>200 \mathrm{lU} / \mathrm{ml}$ as positive, $200 \mathrm{lU} / \mathrm{ml}$ as borderline and $<200 \mathrm{IU} / \mathrm{ml}$ as normal for ASO titres in the studied population, only $5(10 \%)$ patients had normal ASOT levels, $20(40 \%)$ patients had borderline ASOT and 25(50\%) patients had titres above $200 \mathrm{lU} / \mathrm{ml}$. The CRP levels of $>6 \mathrm{mg} / \mathrm{l}$ was considered as high, $6 \mathrm{mg} / \mathrm{l}$ as borderline and $<6 \mathrm{mg} / \mathrm{l}$ as normal titers of CRP; only $3(6 \%)$ patients had normal, 4(8\%) had borderline and 43 (86\%) patients had high CRP levels.

On comparison of ASOT levels with clinical symptoms of RHD i.e. carditis and arthralgia, there was a significant association observed between ASO titres and carditis ( $p$-value $=0.028$ ) whereas no statistically significant link was found between ASOT and arthralgia ( $p$-value $=0.473$ ) (Table-I).

Furthermore, in our study, CRP levels were compared with the same clinical symptoms of carditis and arthralgia. There was significant association found between CRP with carditis ( $p$-value 0.020 ) but no significant association was found in between CRP and arthralgia with $\mathrm{p}$-value 0.574 (Table-II). In this study, ASOT and CRP levels were measured and there was a significant association in between these two parameter with p-value as shown in Table-III.

\section{DISCUSSION}

Acute rheumatic fever (ARF) is characterized by an immune response to Group A streptococcus (GAS) pyogenes bacterial infection. ${ }^{1}$ Carditis and arthralgia are two important manifestations of ARF, and are also included in the Jones diagnostic criteria. If untreated or sub-treated carditis can transform into rheumatic heart disease (RHD) that is characterized by permanent damage to the valves of the heart. ${ }^{1}$

Early diagnosis of RF is vital to inhibit progression of disease towards its complications. Diagnosis of AFR is based on both clinical as well as laboratory criterion. Important laboratory parameters include ASOT, CRP and ESR.

\begin{tabular}{|l|c|c|c|c|}
\hline \multirow{2}{*}{ ASOT } & \multicolumn{2}{|c|}{ Carditis } & \multicolumn{2}{c|}{ Arthralgia } \\
\hline Normal $(<200)$ & Yes & No & Yes & $1(14.3 \%)$ \\
\hline Borderline (200) & $2(4.5 \%)$ & $2(33.3 \%)$ & $4(9.3 \%)$ & $4(57.1 \%)$ \\
\hline High (>200) & $18(40.9 \%)$ & $3(50 \%)$ & $16(37.2 \%)$ & $2(28.6 \%)$ \\
\hline p-value & $24(54.5)$ & $1(16.7 \%)$ & $23(53.5 \%)$ & 0.473 \\
\end{tabular}

Table-I. Comparison of ASOT with carditis and arthralgia

\begin{tabular}{|l|c|c|c|c|}
\hline \multirow{2}{*}{ CRP } & \multicolumn{2}{|c|}{ Carditis } & \multicolumn{2}{c|}{ Arthralgia } \\
\cline { 2 - 5 } & Yes & No & Yes & $0(0 \%)$ \\
\hline Normal $(<6)$ & $2(4.5 \%)$ & $1(16.7 \%)$ & $3(6.8 \%)$ & $0(0 \%)$ \\
\hline Borderline (6) & $2(4.5 \%)$ & $2(33.3 \%)$ & $4(9.1 \%)$ & $6(100 \%)$ \\
\hline High $(>6)$ & $40(90.9 \%)$ & $3(50 \%)$ & $37(84.1 \%)$ & 0.574 \\
\hline p-value & & 0.020 & & \\
\hline
\end{tabular}

Table-II. Comparison of C-reactive protein (CRP) with carditis and arthralgia

\begin{tabular}{|l|c|c|c|}
\hline \multirow{2}{*}{} & \multicolumn{3}{|c|}{ CRP } \\
\hline Normal $(<200)$ & Normal (<6) & Borderline (6) & High (>6) \\
\hline Borderline (200) & $0(0 \%)$ & $1(25 \%)$ & $25(58.1 \%)$ \\
\hline High (>200) & $2(66.7 \%)$ & $1(25 \%)$ & $16(37.2 \%)$ \\
\hline
\end{tabular}


ASOT points towards infection caused by Streptococcus Pyogenes group A (GAS); CRP and ESR are non-specific markers of inflammation. In the current study, we enrolled the pediatric patients of AFR and measured serum levels of ASOT and CRP. These patients were further divided into four groups on the basis of presence or absence of two important clinical symptoms i.e. carditis and arthralgia. ASOT and CRP levels were compared in these groups in order to establish an association to see if these laboratory markers and their levels correlate with these two serious disease manifestations.

Most of the patients exhibited high ASOT levels in this study. Similar observations were made by Kotby et al with significantly high ASOT in ARF (mean 1334.9). ${ }^{16}$ In this study, we observed a significant association between ASOT levels and carditis with 24 (54.54\%) patients expressing high ASO titres as compared to only 2 patient expressing normal ASOT. In the current study, ASOT showed no significant association with arthralgia. This study was partially in agreement with Roodpeyma et al. who also failed to establish any link between ASOT and severity of any clinical manifestation including number of valves involved. ${ }^{17}$

When CRP levels were studied in our study group suffering from carditis, a significant association was established between patients suffering from carditis and CRP levels. This indicates that CRP in spite of being non-specific marker gives an insight for undergoing cardiac inflammation. Our findings were in agreement with a study by Habeeb et al. who measured the levels of hsCRP in acute rheumatic carditis and patients with chronic rheumatic heart disease and compared them with control group. CRP levels were significantly elevated in patients suffering from acute carditis and also correlated with the degree of valvular involvement. ${ }^{15}$ In a similar study carried out in 2006, Chiu-Braga et al. measured the levels of CRP in patients with RHD and reported a significantly elevated hs-CRP levels in these patients compared with controls. ${ }^{18}$ Golbasi et al. evaluated levels of CRP in patients with chronic rheumatic valve disease, prosthetic valve disease and healthy subjects and reported significantly higher levels of hs-CRP in patients with chronic rheumatic heart disease than in patients with prosthetic valve(s) and healthy subjects. ${ }^{19}$

In the present study, CRP levels showed a nonsignificant association with arthralgia. Similar findings were reported by Roodpeyma et al. who found no significant association between clinical manifestations and laboratory parameter. ${ }^{17}$ One plausible explanation is absence of underlying inflammation in the involved joint, making polyarthralgia more of a non-specific symptom and not correlating with Inflammatory markers.

To conclude, ASOT and CRP are important laboratory parameters reflecting undergoing infection (caused by Streptococcus pyogenes A) and inflammation in patients of ARF. Both ASOT and CRP levels correlate significantly with carditis while arthralgia is not related to both laboratory parameters in children suffering from ARF. Rising levels of ASOT and CRP in ARF patients might be used as an indicator of involvement of heart tissues and therefore can be used to monitor transition of rheumatic carditis into rheumatic heart disease.

Copyright $\odot 07$ Dec, 2019.

\section{REFERENCES}

1. Marijon E, Mirabel $M$, Celermajer DS, Jouven $X$. Rheumatic heart disease. The Lancet. 2012 Mar 10; 379(9819):953-64.

2. Lee KY, Rhim JW, Kang JH. Kawasaki disease: Laboratory findings and an immunopathogenesis on the premise of a. Yonsei medical journal. 2012 Mar 1; 53(2):262-75.

3. RHD Australia (ARF/RHD writing group), National heart foundation of Australia and the Cardiac Society of Australia and New Zealand. Australian guideline for prevention, diagnosis and management of acute rheumatic fever and rheumatic heart disease (2nd edition) 2012. Available from: https://www.rhdaustralia. org.au/arf-rhd-guideline.

4. Gewitz MH, Baltimore RS, Tani LY, Sable CA, Shulman ST, Carapetis J, Remenyi B, Taubert KA, Bolger AF, Beerman L, Mayosi BM. Revision of the Jones Criteria for the diagnosis of acute rheumatic fever in the era of Doppler echocardiography: A scientific statement from the American Heart Association. Circulation. 2015 May 19; 131(20):1806-18. 
5. Dobson J, Steer AC, Colquhoun S, Kado J. Environmental factors and rheumatic heart disease in Fiji. Pediatric cardiology. 2012 Feb 1; 33(2):332-6.

6. Wallace M, Garst PD, Papadimos TJ, Oldfield EC. The return of acute rheumatic fever in young adults. Jama. 1989 Nov 10; 262(18):2557-61.

7. Longo-Mbenza B, Bayekula M, Ngiyulu R, Kintoki VE, Bikangi NF, Seghers KV, Lukoki LE, Mandundu MF, Manzanza M, Nlandu Y. Survey of rheumatic heart disease in school children of Kinshasa town. International journal of cardiology. 1998 Feb 28; 63(3):287-94.

8. Stanevicha V, Eglite J, Sochnevs A, Gardovska D, Zavadska D, Shantere R. HLA class II associations with rheumatic heart disease among clinically homogeneous patients in children in Latvia. Arthritis Res Ther. 2003 Dec; 5(6): R340.

9. Jones, T.D. The diagnosis of rheumatic fever. JAMA. 1944; $481-4$.

10. Ferrieri, P. Proceeding of the Jones criteria workshop. 2002; 106(9):2521-3.

11. Dobson J, Steer AC, Colquhoun S, Kado J. Environmental factors and rheumatic heart disease in Fiji. Pediatric cardiology. 2012 Feb 1; 33(2):332-6.

12. Parrillo, S.J. Rheumatic fever. Emedicine. 2007. [document on the internet]. WebMD. Available at: < http://www.emedicine.com/emerg/topic-509.html>.
13. Naher A, Miah R, Jahan Y. Interpretation of AntiStreptolysin $O$ (ASO) Titer and Erythrocyte Sedimentation Rate (ESR), C-reative Protien (CRP) for the Diagnosis of Rheumatic Fever. Orion. 2002 May; $12: 1-3$.

14. Pepys MB, Hirschfield GM. C-reactive protein: A critical update. The Journal of clinical investigation. 2003 Jun 15; -111(12):1805-12.

15. Habeeb NM, Al Hadidi IS. Ongoing inflammation in children with rheumatic heart disease. Cardiology in the Young. 2011 Jun; 21(3):334-9.

16. Kotby AA, Habeeb NM, El Elarab SE. Antistreptolysin 0 titer in health and disease: Levels and significance. Pediatric reports. 2012 Jan 2; 4(1).

17. Roodpeyma S, Kamali Z, Zare R. Rheumatic fever: The relationship between clinical manifestations and laboratory tests. Journal of paediatrics and child health. 2005 Mar; 41(3):97-100.

18. Chiu-Braga YY, Hayashi SY, Schafranski M, MessiasReason IJ. Further evidence of inflammation in chronic rheumatic valve disease (CRVD): High levels of advanced oxidation protein products (AOPP) and high sensitive C-reactive protein (hsCRP). International journal of cardiology. 2006 May 10; 109(2):275-6.

19. Golbasi Z, Uçar O, Keles T, Sahin A, Çagli K, Çamsari A, Diker E, Aydogdu S. Increased levels of high sensitive C $\square$ reactive protein in patients with chronic rheumatic valve disease: Evidence of ongoing inflammation. European journal of heart failure. 2002 Oct; 4(5):593-5.

\begin{tabular}{|c|c|c|c|}
\hline \multicolumn{4}{|c|}{ AUTHORSHIP AND CONTRIBUTION DECLARATION } \\
\hline Sr. \# & Author(s) Full Name & Contribution to the paper & Author(s) Signature \\
\hline 1 & Sana Zainab & $\begin{array}{l}\text { Data analysis, Study design, } \\
\text { Drafting manuscript. }\end{array}$ & \\
\hline 2 & Nida Saleem & $\begin{array}{l}\text { Study design, drafting \& } \\
\text { review. }\end{array}$ & \\
\hline 3 & Adil Manzoor & $\begin{array}{l}\text { Study design, drafting and } \\
\text { review. }\end{array}$ & \\
\hline 4 & Saba Khaliq & Drafting and manuscript. & \\
\hline 5 & Anum Wasim & Drafting and manuscript. & \\
\hline 6 & Shakila Akram & Drafting and manuscript. & \\
\hline 7 & Farhana Shehzad & $\begin{array}{l}\text { Data analysis, Study design, } \\
\text { drafting \& review. }\end{array}$ & \\
\hline
\end{tabular}

